\title{
Impact of RNAi-Targeted Silencing of Survivin and Hypoxia-Inducible Factor-1a on the Biological Behaviors of Gastric Cancer SGC-7901 Cells In Vitro
}

\section{Runhong Mu}

Beihua University

Yinlin Ge

Beihua University

Mingcheng Li ( $\sim$ limingcheng1964@163.com )

Beihua University https://orcid.org/0000-0003-2640-4305

Binxian Li

Beihua University

\section{Research Article}

Keywords: RNAi, gastric cancer, HIF-1a, survivin, metastasis, migration

Posted Date: May 5th, 2021

DOI: https://doi.org/10.21203/rs.3.rs-463201/v1

License: (c) (i) This work is licensed under a Creative Commons Attribution 4.0 International License. Read Full License 


\section{Abstract}

Hypoxia-inducible factor-1 (HIF-1) plays crucial roles in the primary transcriptional responses to hypoxia stress by modulating hypoxia gene expression. Survivin is regarded as an effector downstream of HIF-1 that promotes cell survival under hypoxia conditions. HIF-1a and survivin are proposed as potential targets in the treatment of gastric cancer. This study was designed to investigate the anticancer effects of RNA interference targeting survivin and HIF-1a on the gastric cancer cell line, SGC-7901 under hypoxia. In this study, cultured cells were divided randomly into four groups: a blank control group, a scrambled siRNA (SCR) control group, a siRNA-Survivin group (ss group) and a siRNA-Survivin+siRNA-HIF-1a group (sis+siH group). The siRNA targeting survivin and/or HIF-1 a genes were transfected into SGC-7901 cells. The expression of survivin and HIF-1 a was identified by RT-PCR and Western blotting assay. Apoptosis was determined by flow cytometry. The invasion and migration abilities of the cells were evaluated by transwell and wound healing assays, respectively. Cell growth curves were determined by MTT assay at $48 \mathrm{~h}$ indicated that the viability of the SGC-7901 cells was inhibited in a time-dependent manner with a highest inhibitory rate of $82.1 \pm 0.85 \%$ at $48 \mathrm{~h}$. The siRNA targeting the survivin gene decreased the expression of survivin and the combined transfection of siRNA targeting survivin and HIF-1a downregulated the expression of both survivin and HIF-1a $(P<0.05)$. Compared with the blank control group, the combined siRNA groups exhibited obvious features with decreased invasion and migration abilities $(P$ $<0.05)$. The apoptosis rate increased and the cell proliferation decreased following gene silencing $(P<$ 0.05). The down-regulation of survivin and HIF-1 a may induce an anticancer effect in SGC-7901 cell lines by enhancing cell apoptosis and decreasing proliferation, migration and invasion ability.

\section{Introduction}

Gastric cancer is the second most common cancer worldwide[1]. Patients with gastric cancer at even early stage usually have distant metastasis and poor prognosis despite the combined therapy with surgery, chemotherapy and radiotherapy [2]. Hypoxia is a shared feature and form of physiological stress on various cancers. Hypoxia stress can facilitate adaptive changes in tumor cells, which eventually leads to increasing tumor growth, invasion and metastasis [3, 4]. Accumulating evidence suggests that hypoxia, resulting from highly active tumor cell proliferation, is related to poor prognosis and development of resistance to chemotherapy and radiotherapy[5, 6]. Hypoxia-inducible factor-1 (HIF-1) is an essential transcriptional regulator, also known as hydrocarbon receptor nuclear translocator, which plays crucial roles in the primary transcriptional responses to hypoxia stress by modulating hypoxia gene expression [6]. Structurally, HIF1 consists of HIF-1a and HIF-1 $\beta$ subunits [7]. These heterodimeric transcription molecules activate a series of phosphoglycerate kinase and vascular endothelial growth factor (VEGF) genes by response to hypoxia[8]. Survivin, a member of the inhibitor of apoptosis (IAP) family, acts as a key regulator of angiogenesis in addition to to tumor progression[9].

RNA interference (RNAi) is a mechanism of transcriptional regulation for specific gene expression silencing in the majority of eukaryotic cells $[10,11]$. The process is mediated by small RNA (siRNA) molecules 21-23 nucleotides in length $[12,13]$. There is emerging evidence that RNAi plays an important 
regulatory role in the articulated molecular mechanism triggered by hypoxia stress. Our previous studies demonstrated that RNAi targeting survivin in BGC-823 cell lines may attenuate the anti-proliferative and apoptosis-inducing effects under hypoxia [14]. However, overexpression of HIF-1a was associated with the poor prognosis in gastric cancer [15]. Currently, it is well known that HIF-1 transactivates the survivin gene by directly targeting the survivin promoter. Both HIF-1a and survivin are activated, along with high over expression of VEGF in tumor cells under hypoxia, which results in endothelial cell proliferation, migration and neovascularizaiton. HIF-1 $a$ and survivin are proposed as potential targets in the treatment of gastric cancer. Accordingly, we sought to investigate how RNAi targeting HIF-1 a mediates the growth of gastric cancer cell line SGC-7901 combined with survivin.

\section{Materials And Methods}

\section{Cell culture and hypoxia treatment}

The human gastric cancer cell line SGC-7901 was obtained from the China Center for Type Culture and was maintained in RPMI-1640 medium (Hyclone, Beijing, China) containing 10\% fetal bovine serum (Sijiqing Bio. Co., Ltd., Hangzhou, China) and $1 \%$ penicillin/streptomycin, in a $5 \% \mathrm{CO}_{2}$ humidified atmosphere at $37^{\circ} \mathrm{C}$ incubation. The medium was changed at alternate days and cells were harvested at $70-80 \%$ of confluency for experimental purposes. After seeding for $24 \mathrm{~h}$, cells were incubated in normal or hypoxic conditions for a further $48 \mathrm{~h}$ (for hypoxic treatment, cells were maintained in a hypoxia incubator of $1 \%$ oxygen concentration infused with $5 \% \mathrm{CO}_{2}$ and nitrogen gas mixture).

\section{RNA interference and groups}

Two pairs of siRNAs were designed against human HIF-1a and survivin, as follows: siRNA-HIF-1a, 5'CCAUAUAGAGAUACUCAAATT-3' (sense) and 5'-UUUGAGUAUC UCUAUAU GGTT-3' (antisense); siRNAsurvivin, 5'-GGCUGGCUUCAUCCACUGCTT-3' (sense) and 5'- GCAGUGGAUGAAGCCAGCCTT-3' (antisense).

The sequences 5'-UUGAUGUGUUUAGUCGCUATT-3' (sense) and 5'-UAGCGACUAAACACAUCAATT-3' (antisense), named scrambled siRNA (SCR) were used as a negative control. 3'-

Fluorescein amidite (FAM) fluorescence-labeled SCR was utilized to detect the transfection efficiency. All siRNAs were chemically synthesized by Gen. Co., Ltd. (Shanghai, China).

The cultured cells were randomly divided into four groups: a blank control group, a siRNA-Survivin group (ss group), a siRNA-Survivin+siRNA-HIF-1a group (sis+siH group) and a SCR control group. For siRNA transfection, SGC-7901 cells were prepared on 6-well plates and incubated overnight to achieve $80-90 \%$ confluency. The cells were transfected with $100 \mathrm{nmol} / \mathrm{L}$ siRNAs using Hifectin囚 (Applied Gen Co., Ltd., Beijing, China) according to the protocol provided by the manufacturer. Transfection efficiency rates $₫$ cells displaying green fluorescence $\$ total count cells $\times 100 \rrbracket$. Subsequently, the exponentially growing SGC-7901 cells were maintained under hypoxic conditions for further experiments. Three independent repeats were conducted for all experiments. 


\section{Cell viability assay}

The 3-[4, 5-dimethylthiazol-2-yl]-2, 5-diphenyltetrazolium bromide (MTT) (Funakoshi Co., Tokyo, Japan) assay was performed to evaluate cell proliferation. SGC-7901 cells were seeded on 96-well plates at an optimal density $\left(3 \times 10^{3}\right.$ cells per well) and incubated overnight. After another 48 -h incubation in normal or hypoxic conditions, cells were treated with $20 \mu \mathrm{L} \mathrm{MTT}(5 \mathrm{mg} / \mathrm{mL})$ and $150 \mu \mathrm{L}$ dimethyl sulfoxide (DMSO). The optical density (OD) value of each well was measured at $490 \mathrm{~nm}$ using a $2100 \mathrm{C}$ ELISA Reader (Rayto Sciences Co., Ltd. Shanghai, China). The cell viability curve of the four groups was drawn. The cell proliferation inhibition rate $=(1$-average OD value experimental group/average OD value control group $) \times$ $100 \%$.

\section{Reverse transcription polymerase chain reaction (RT-PCR)}

The primers were as follows: sense, 5'-GCAAGCCCTGAAAGCG-3' and antisense, 5'GGCTGTCCGACTTTGA-3' for HIF-1a (240 bp); Sense, 5'-AACAGCCGAG ATGACCTCC-3' and antisense, 5'AACTTCAGGTGGATGAGGAGAC-3' for survivin (421 bp); GAPDH (glyceraldehyde-3-phosphate dehydrogenase) sense, 5'-TGAAGGTCGGAGTCAACGGATTTGGT-3' and antisense, 5'-CATGTGGG CCATGAGGTCCACCAC-3' for the internal reference (983 bp). Total mRNA was isolated with TRIzol ${ }^{\circledR}$ reagent (Invitrogen Life Techonology, USA), and CDNA was prepared with the GoScript ${ }^{\text {TM }}$ Reverse Transcription System kit (Promega Biotech Co., Ltd., USA) according to the manufacturer's instructions. The PCR program was as follows: denaturation at $95^{\circ} \mathrm{C}$ for $5 \mathrm{~min} ; 30$ cycles of $94^{\circ} \mathrm{C}$ for $30 \mathrm{~s}$, annealing at $50^{\circ} \mathrm{C}$ for $30 \mathrm{~s}$ and $72^{\circ} \mathrm{C}$ for $1 \mathrm{~min}$, with a final step at $72^{\circ} \mathrm{C}$ for $5 \mathrm{~min}$. PCR products were separated using $2 \%$ agarose gel, and the bands were scanned and the relative mRNA expression levels were determined by comparing with the expression of GAPDH.

\section{Western blotting analysis}

After treatments, total protein was extracted from cells using radio -immunoprecipitation assay (RIPA) buffer (Beyotime Biotech Co., Ltd., Wuhan, China) and the level of protein was determined using the bicinchoninic acid assay method. Equal amounts of protein lysates $(50 \mu \mathrm{g})$ were separated by sodium dodecyl sulfate polyacrylamide gel electrophoresis (SDS-PAGE) and transferred to polyvinylidene fluoride membranes (EMD Millipore Co., Hayward, CA, USA). The membranes were blocked with $5 \%$ skimmed milk for $1 \mathrm{~h}$ and then incubated at $4^{\circ} \mathrm{C}$ overnight with monoclonal rabbit anti-mouse antibodies against HIF-1a, GAPDH (Boster Co., Ltd., Wuhan, China) and survivin (Biosynthesis Co., Ltd., Beijing, China). On the following day, the membranes were washed with TBST and incubated for $1 \mathrm{~h}$ at room temperature with the secondary peroxidase-labeled goat anti-rabbit antibody (Boster Co., Ltd, Wuhan, China) diluted to 1:2000 in skimmed milk/TBST. The protein bands were visualized by enhanced chemi-luminescence and the band intensity was measured using Quantity One v4.6.2 software (Bio-Rad, California, USA). Quantitative analysis of the relative levels of target proteins was determined using the NIH ImageJ software. 
For analysis of apoptosis, an annexin V-FITC apoptosis detection kit was used (Invitrogen, USA). After treatment for 48 h, SGC-7901 cells were harvested, washed twice with PBS and resuspended in $500 \mu \mathrm{L}$ of binding buffer. Cell suspensions were then incubated with $5 \mu \mathrm{L}$ of annexin V-FITC and $5 \mu \mathrm{L}$ of propidium iodide (PI) for $10 \mathrm{~min}$ at room temperature away from light. The apoptotic rates were calculated based on the number of these transfected gastric cancer cells in the apoptotic state and evaluated immediately by flow cytometry (BD Biosciences, Franklin Lakes, $\mathrm{NJ}$ ) . The mean fluorescence intensity of annexin-VFITC/PI was determined by flow cytometry. Then the apoptotic rates were calculated at the mean fluorescence intensity. At last, the results were quantified using WinMDI 2.9 analysis software.

\section{Wound healing assay}

Scratch (wound-healing) assays were performed to determine cell migration ability. SGC-7901 cells were seeded in plates at a density of $3 \times 10^{5}$ cells/well and incubated overnight before being treated as described above. After 24 hours, cells were maintained in normoxic or hypoxic conditions and scratched using a sterile $200-\mu \mathrm{L}$ tip to create a wound. Cells were then washed three times with PBS to remove debris, and were cultured in a serum-free medium for further 24 hours. The width of the wound area was monitored and measured at more than three positions per scratch by using microscopy to compare the migration ratios among the groups.

\section{Invasion assay}

Matrigel invasion assays were employed to assess the invasion of SGC-7901 as previously described. Treated cells were incubated overnight in the serum-free medium. Then, $50 \mu \mathrm{L}$ Matrigel (BD Biosciences, San Jose, CA) was overlaid and maintained at $37^{\circ} \mathrm{C}$ for 1 hour inside transwell filters with a membrane pore size of $8.0 \mu \mathrm{m}$. Next, $5 \times 10^{4}$ of treated cells suspended in the serum-free RPMI- 1640 medium were added in the upper chambers and the bottom chamber of each well contained only RPMI-1640 medium with $10 \%$ FBS. After incubation in normoxic or hypoxic conditions for $12 \mathrm{~h}$, cells on the upper surface were removed using a cotton swab. Cells on the lower surface of the membrane were fixed ( $4 \%$ paraformaldehyde) and stained with $0.1 \%$ crystal violet. Cells on the lower surface of the filter were visualized and photographed under the microscope, and the relative numbers were counted (five distinct fields per insert).

\section{Statistical analysis}

Data were expressed as mean values with standard error of the mean ( \pm SEM). Statistical analysis was performed using Student's $t$ test with SPSS11.0 for Windows. All experiments were performed in triplicate. Differences were considered statistically significant at $P<0.05$.

\section{Results}

\section{Rates of siRNA transfection}


We observed the expression of transfection efficiency of siRNA under fluorescence microscopy for $6 \mathrm{~h}$ in SGC-7901 cells. The results showed a higher transfection efficiency with more than $80 \%$ of cells displaying green fluorescence due to the fluorescent-labeled siRNA in both ss group and sis + siH group compared with a SCR control group and blank control group (Fig. 1).

\section{Effect of HIF-1a or/and survivin RNAi on SGC-7901 cell viability under hypoxia}

Cell growth curves determined by MTT assay at $48 \mathrm{~h}$ showed that cell viability was inhibited in a timedependent manner with the highest inhibitory rate at $82.1 \pm 0.85 \%$ after $48 \mathrm{~h}$ in the $\mathrm{siH}+$ sis group compared with the control group and the SCR control group $(P<0.05$, Fig. 2$)$.

\section{Individual inhibitory effects of siRNAs targeting HIF-1a and survivin under hypoxia}

We further evaluated the silencing effects of siRNA-HIF-1a and siRNA-survivin in SGC-7901 cell. After transfection, cells were maintained under hypoxia. After $48 \mathrm{~h}$, the expression levels of HIF-1a and survivin were determined by RT-PCR and Western blotting analysis. The findings showed that the expressions of HIF-1a and survivin were inhibited in the siH and sis groups at the mRNA and protein levels. The expression levels of HIF-1a and survivin mRNA and protein were significantly reduced simultaneously compared to control cells $(P<0.05$, Fig. 3 and Fig. 4$)$.

\section{Effect of HIF-1a or/and survivin RNAi on SGC-7901 cell apoptosis under hypoxia}

Apoptosis was assessed for $48 \mathrm{~h}$ after transfection by staining cells with Annexin V/PI and analyzed using an FCM. The strongest apoptotic signals were identified in the $\mathrm{siH}+$ sis groups and the percentages of apoptotic cells were $11.5 \pm 2.5$. The results indicated that the apoptosis rates of SGC-7901 cells in the $\mathrm{siH}+$ sis groups were higher than those in the control group $(P<0.05$, Fig. 5$)$.

\section{Effect of HIF-1a or/and survivin RNAi on migration ability of SGC-7901 cells under hypoxia}

Woundhealing assays were performed and the width of the wounded area measured at more than three positions per scratch by microscopy at $12 \mathrm{~h}$ and $24 \mathrm{~h}$. A significant difference was found in the migration ratios amongst the groups. The migration of SGC-7901 cells of the siH + sis group (198.6 $\pm 14.80 \mathrm{~mm})$ decreased by $45.48 \%(P<0.05)$ compared with control group $(464.0 \pm 15.04 \mathrm{~mm})$, whilst the SCR group showed no significant difference (497.4 $\pm 25.57 \mathrm{~mm}, P>0.05$, Fig. 6$)$.

\section{Effect of HIF-1a or/and survivin RNAi on invasive ability of SGC-7901 cells under hypoxia}

In the meanwhile, the invasion assay revealed that the invasive number of SGC-7901 cells on the control and SCR groups were $91.33 \pm 4.055$ and $85.33 \pm 4.256$ respectively, whereas the invasion cells were 24.41 \pm 2.41 in the $\mathrm{siH}+$ sis groups $(P<0.05$, Fig. 7$)$.

\section{Discussion}


RNAi technique has been widely used in the functional analysis of mammalian genes using synthetic 1923-nucleotides double-stranded RNAs as siRNA $[15,16,17]$. RNAi as a target-specific gene suppression technology has provided a promising way for gene therapy in various diseases, particularly in cancer [18, $19,20]$. The efficiency of RNAi on the same target usually shows great difference. One of the critical preconditions for RNAi therapy is the appropriate siRNA that can efficiently knock down the expression of target genes [21, 22]. While the activated oncogene mRNA was be effectively inhibited by RNAi technology, the tumor cell growth, proliferation, invasion, vascularization and extravasation were also be inhibited $[23,24,25]$. Tamura et al. reported that intraperitoneal administration of ST6GalNAc I siRNAliposome significantly inhibited peritoneal dissemination of gastric cancer in vitro [26]. Li et al. reported that the survivin-targeting siRNA (siRNA-survivin) in three cancer cell lines, survivin protein expression markedly decreased whereas apoptotic rates noticeably increased [27].

In this study, we employed two pairs of siRNAs targeting survivin and HIF-1a mRNA separately which were then transfected into SGC-7901 cells. On the basis of relative expression of mRNA and protein levels, our findings confirmed that the two siRNAs were highly efficient in suppressing survivin and HIF-1a expression in SGC-7901 cells. The confirmation of efficient siRNA targeting human survivin and HIF-1a in this study warrants further research on survivin and HIF-1a. Our studies have shown that under hypoxic conditions, the expression of HIF-1a was higher in SGC-7901 cells and the results indicated a highefficiency transfection with more than $80 \%$ of cells displaying green fluorescence. HIF- 1 a, as a major transcriptional factor activated by hypoxia, triggers a series of oncogenes in tumor development $[28,29]$. By activation of a large number of downstream target genes, tumor cells adapt to the hypoxia settings and continue to survive, followed by malignant proliferation, metastasis and even resistance to chemotherapy [30, 31]. HIF-1a-survivin pathway provides a means whereby gastric cancer cells can survive and grow under hypoxia conditions, suggesting the pathway as a therapeutic target for the gene treatment of gastric cancer $[32,33]$. This finding was in an agreement with the publication of others [34, 35].

We therefore explored the impact of further knockdown on the expression of survivin and HIF-1a in the gastric epithelial cell line SGC-7901. Compared with the SCR and the blank control group, the inhibitory rate of SGC-7901 had significantly lower expression levels of survivin and HIF-1a on the sis $+\mathrm{siH}$. Compared with the blank control group, the expression levels of survivin and HIF-1a mRNA were significantly decreased along with survivin and HIF-1a proteins in the sis + siH group. The flow cytometry results showed that the apoptotic rate of SGC-7901 cells in the sis + siH group was significantly higher than those in the SCR and blank control groups. The results of the transwell migration assay indicated that the numbers of migration cells in the sis $+\mathrm{siH}$ group were significantly lower than those in the control group.

There are some limitations to our study. We did not detect the Bcl-2/Bax ratio. More experiments are needed to determine the expression of $\mathrm{Bcl}-2$ and $\mathrm{Bax}$ and the exact mechanism underlying this pathway.

\section{Conclusion}


Our findings suggest that RNAi targeting survivin and HIF-1a dramatically reduced cell growth and increased apoptosis in gastric cancer cell in vitro. RNAi against survivin and HIF-1 a may be a potentially novel approach for the prevention and treatment of gastric canner. However, the precise underlying mechanisms of survivin and HIF-1a RNAi on proliferation and apoptosis in SGC-7901 cells remain to be fully determined and require further investigation.

\section{Declarations}

Acknowledgements We thank three anonymous reviewers for excellent criticism of the article.

Funding This study was supported in part by the Health Developing Program in Jilin Province, China (Grant Nos. 20132099; 20180101142JC) and the Science and Technology Development Program of Jilin Province, China (Grant Nos. 20190304101YY and 20190301014NY). This work was supported by a Grant from the Science and Technology Development Plan of Jilin Province (Grant No. 20190303047SF).

\section{Compliance with ethical standards}

Conflict of interest The authors declare no competing interests.

The authors alone are responsible for the content and writing of the paper.

Ethical approval No applicabe.

Informed consent All authors consent to the submission of this manuscript to the Journal, Molecular Biology Reports.

Author contributions Runhong Mu designed the experiments and wrote a draft manuscript. Binxian Li and Mingcheng Li analyzed, interpreted the results of the experiments and revised the manuscript. Yinlin $\mathrm{Ge}$ performed the experiments. All authors read and approved the final manuscript.

\section{References}

1. Zeng HM, ChenWQ, Zheng RS, Zhang SW, John SJ, Xiaonong Zou XN et al (2018) Changing cancer survival in China during 2003-15: A pooled analysis of 17 population-based cancer registries. Lancet Glob Health 6(5):e555-e567

2. Fock $\mathrm{KM}$ ( (2014) Review article: the epidemiology and prevention of gastric cancer. Aliment Pharmacol Ther 40:250-260

3. Chau NM, Rogers P, Aherne W, CarrolIV, Collins I, McDonald E et al (2005) Identification of novel small molecule inhibitors of hypoxia-inducible factor- 1 that differentially block hypoxia-inducible factor- 1 activity and hypoxia-inducible factor-1alpha induction in response to hypoxic stress and growth factors. Cancer Res 65(11):4918-4928 
4. Stylianopoulos T, Martin JD, Chauhan VP, Jain SR, Diop-Frimpong B, Bardeesy N et al (2012) Causes, consequences, and remedies for growth-induced solid stress in murine and human tumors. Proc Natl Acad Sci USA 109(38):15101-15108

5. Huang SP, Wu MS, Shun CT, Wang HP, Hsieh CY, Kuo ML et al (2005) Cyclooxygenase-2 increases hypoxia-inducible factor-1 and vascular endothelial growth factor to promote angiogenesis in gastric carcinoma. J Biomed Sci 12(1):229-241

6. Zhao XY, Chen TT, Xia L, Guo M, Xu Y, Yue F et al (2010) Hypoxia inducible factor-1 mediates expression of galectin-1: the potential role in migration/invasion of colorectal cancer cells. Carcinogenesis 31(8):1367-1375

7. Semenza GL (2014) Oxygen sensing, hypoxia-inducible factors, and disease pathophysiology. Annu Rev Pathol: Mech Dis 9:47-71

8. Harris AL (2002) Hypoxia - a key regulatory factor in tumour growth. Nat Rev Cancer 2:38-47

9. Bernd G, Astrid W (2014) Targeting Survivin in Cancer: Novel Drug Development Approaches. BioDrugs 28:27-39

10. Link A, Kupcinskas J (2018) MicroRNAs as Non-Invasive Diagnostic Biomarkers for Gastric Cancer: Current Insights and Future Perspectives. World J Gastroenterol 24(30):3313-3329

11. Mansoori B, Shotorbani SS, Baradaran B (2014) RNA interference and its role in cancer therapy. Adv Pharm Bull 44:313-321

12. Deng Y, Wang CC, Choy KW, Du Q, Chen J, Wang Q et al (2014) Therapeutic potentials of gene silencing by RNA interference: principles, challenges, and new strategies. Gene 538(2):217-227

13. Elbashir SM, Harborth J, Weber K, Tuschl T (2002) Analysis of gene function in somatic mammalian cells using small interfering RNAs. Methods 26:199-213

14. Wang M, Mu RH, Li MC (2018) Effects of silencing survivin and HIF-1a genes with RNAi on proliferation and apoptosis of human gastric cancer BGC-823 cells. J Jilin University (Medicine Edition) 27ه4囚: 457-459 (Abstract in English)

15. Sciabola S, Cao Q, Orozco M, Faustino I, Stanton RV(2013)Improved nucleic acid descriptors for siRNA efficacy prediction. Nucl Acids Res 41: 1383-94

16. Kierans SJ, Taylor CT (2021) Regulation of glycolysis by the hypoxia-inducible factor (HIF): implications for cellular physiology. J Physiol 599(1):23-37

17. Takasaki S (2013) Methods for selecting effective siRNA target sequences using a variety of statistical and analytical techniques. Methods Mol Biol 942:17-55

18. Church DN, Talbot DC (2012) Survivin in solid tumors: rationale for development of inhibitors. Curr Oncol Rep 14:120-128

19. Haussecker D, Kay MA (2015) RNA interference. Drugging RNAi. Science 347:1069-1070

20. Khvorova A, Reynolds A, Jayasena SD (2003) Functional siRNAs and miRNAs exhibit strand bias. Cell 115(2):209-216 
21. Carthew RW, Sontheimer EJ (2009) Origins and Mechanisms of miRNAs and siRNAs. Cell 136(4):642-655

22. Grijalvo S, Alagia A, Jorge AF, Eritja R(2018)Covalent Strategies for Targeting Messenger and NonCoding RNAs: An Updated Review on siRNA, miRNA and antimiR Conjugates. Genes (Basel) 9(2):74. doi: $10.3390 /$ genes 9020074

23. Li L, Lin X, Staver M, Shoemaker A, Semizarov D, Fesik SW et al (2005) Evaluating hypoxia-inducible factor-1alpha as a cancer therapeutic target via inducible RNA interference in vivo. Cancer Res 65:7249-7458

24. Sun JD, Liu Q, Wang J, Ahluwalia D, Ferraro D, Wang Y et al (2012) Selective tumor hypoxia targeting by hypoxia-activated prodrug TH-302 inhibits tumor growth in preclinical models of cancer. Clin Cancer Res 18(3):758-770

25. Tamura A, Nagasaki Y (2010) Smart siRNA delivery systems based on polymeric nanoassemblies and nanoparticles. Nanomedicine (Lond) 5(7):1089-1102

26. Li YH, Chen M, Zhang M, Zhang XQ, Zhang S, Yu CG et al (2014) Inhibitory effect of survivintargeting small interfering RNA on gastric cancer cells. Genet Mol Res 13(3):6786-6803

27. Nallamshetty S, Chan SY, Loscalzo J (2013) Hypoxia: a master regulator of microRNA biogenesis and activity. Free Radic Biol Med 64:20-30

28. Semenza GL (2002) HIF-1 and tumor progression: pathophysiology and therapeutics. Trends Mol Med 8:S62-S67

29. Takahashi R, Tanaka S, Hiyama T, Ito M, Kitadai Y, Sumii M et al (2003) Hypoxia-inducible factor1 alpha expression and angiogenesis in gastrointestinal stromal tumor of the stomach. Oncol Rep 10:797-802

30. Russell DL, lan S, Adrian L (2005) The role of hypoxia-inducible factor-1 in threedimensional tumor growth, apoptosis, and regulation by the insulin-signaling pathway. Cancer Res 65:4147-4152

31. Chiou SK, Moon WS, Jones MK, Tarnawski AS (2003) Survivin expression in the stomach: Implications for mucosal integrity and protection. Biochem Biophys Res Commun 305:374-379

32. Martínez-García D, Manero-Rupérez N, Roberto Q, Korrodi-Gregório L, Soto-Cerrato V (2019) Therapeutic strategies involving survivin inhibition in cancer. Med Res Rev 39(3):887-909

33. Blanc-Brude OP, Mesri M, Wall NR, Plescia J, Dohi T, Altieri DC et al (2003) Therapeutic targeting of the survivin pathway in cancer: Initiation of mitochondrial apoptosis and suppression of tumorassociated angiogenesis. Clin Cancer Res 9:2683-2692

34. Semenza GL (2000) HIF-1: mediator of physiological and pathophysiological responses to hypoxia. J Appl Physiol 88:1474-1480

35. Church DN, Talbot DC (2012) Survivin in solid tumors: rationale for development of inhibitors. Curr Oncol Rep 14:120-128

\section{Figures}




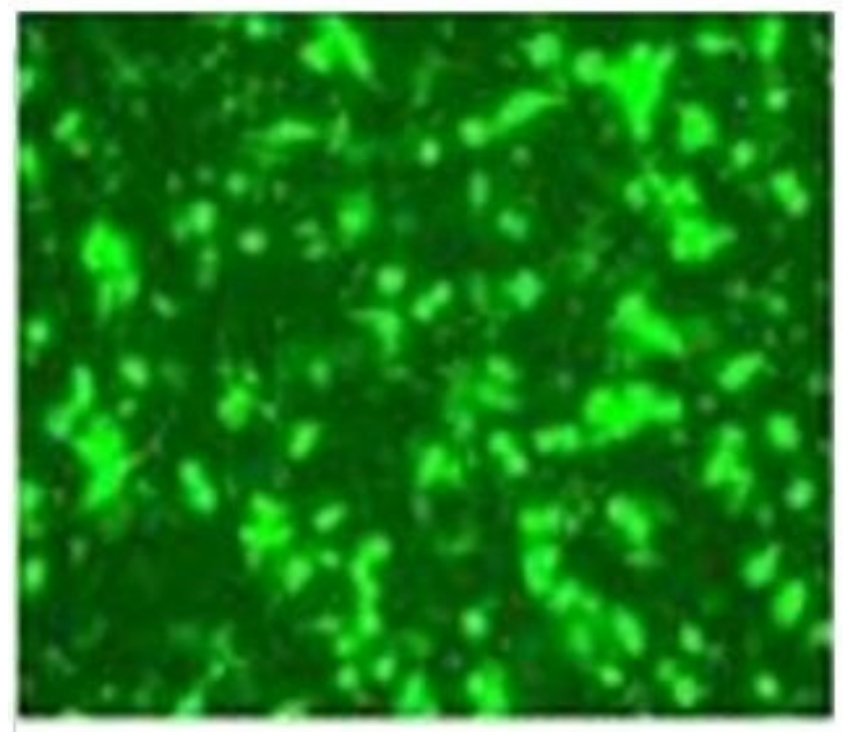

ss group

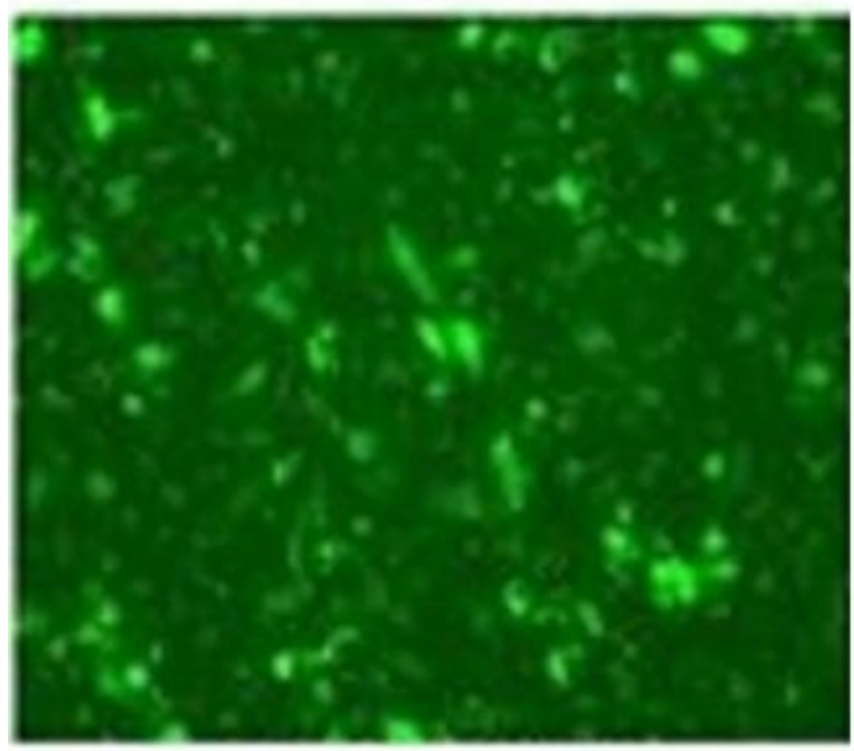

SCR control

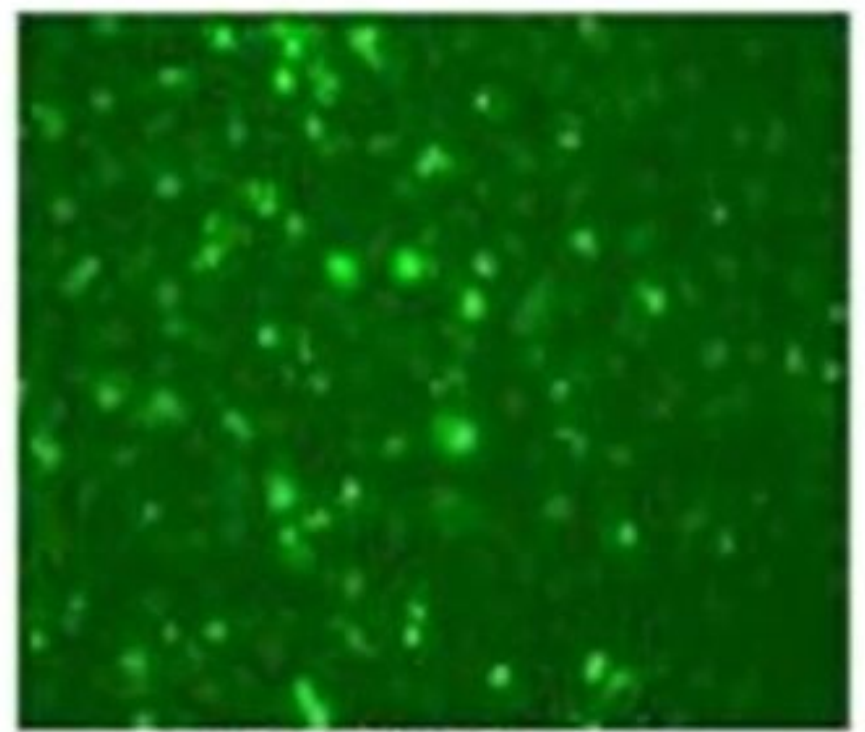

sis + siH group

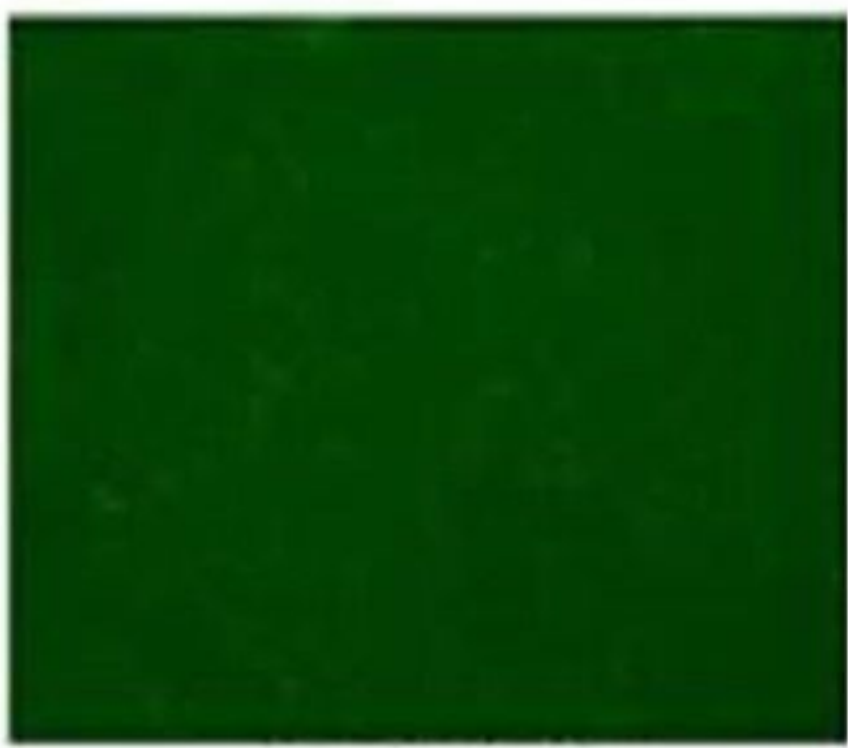

Blank control

Figure 1

Expression of green fluorescence in SGC-7901 cells after transfection for $6 \mathrm{~h}$ due to the fluorescentlabeled siRNA ( $\times 200)$. Note: Data are representative images (magnification $\times 200)$ in individual groups of cells from three separate experiments. 


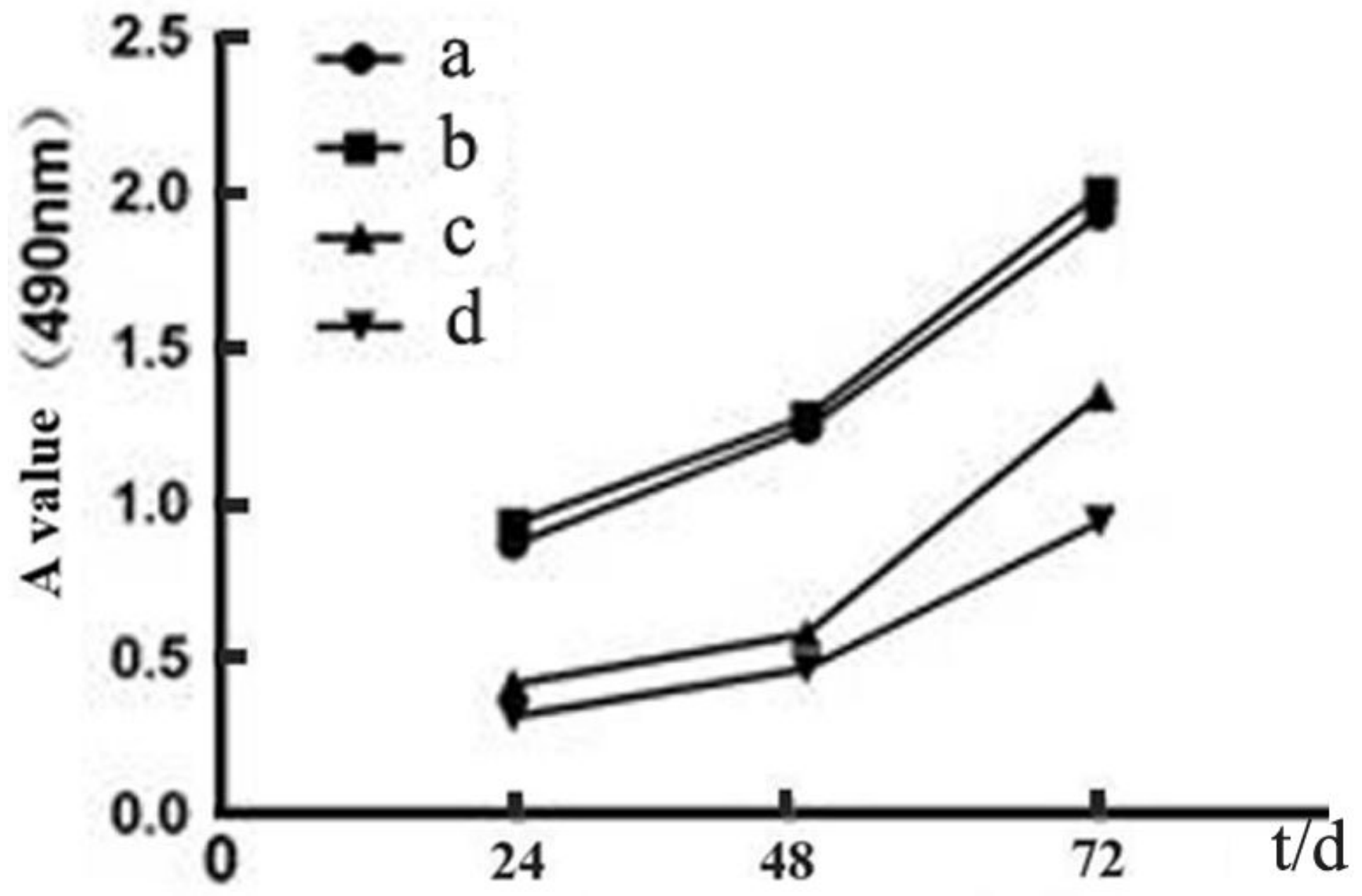

Figure 2

Effect of siRNA on the proliferation of SGC-7901 cells via the MTT assay Note: Line a: Blank control group; Line b: SCR control group; line c: siRNA-Survivin group (ss group); line d: siRNA-Survivin+siRNAHIF-1a group (sis+siH group). *P $<0.05$ vs. the control. 

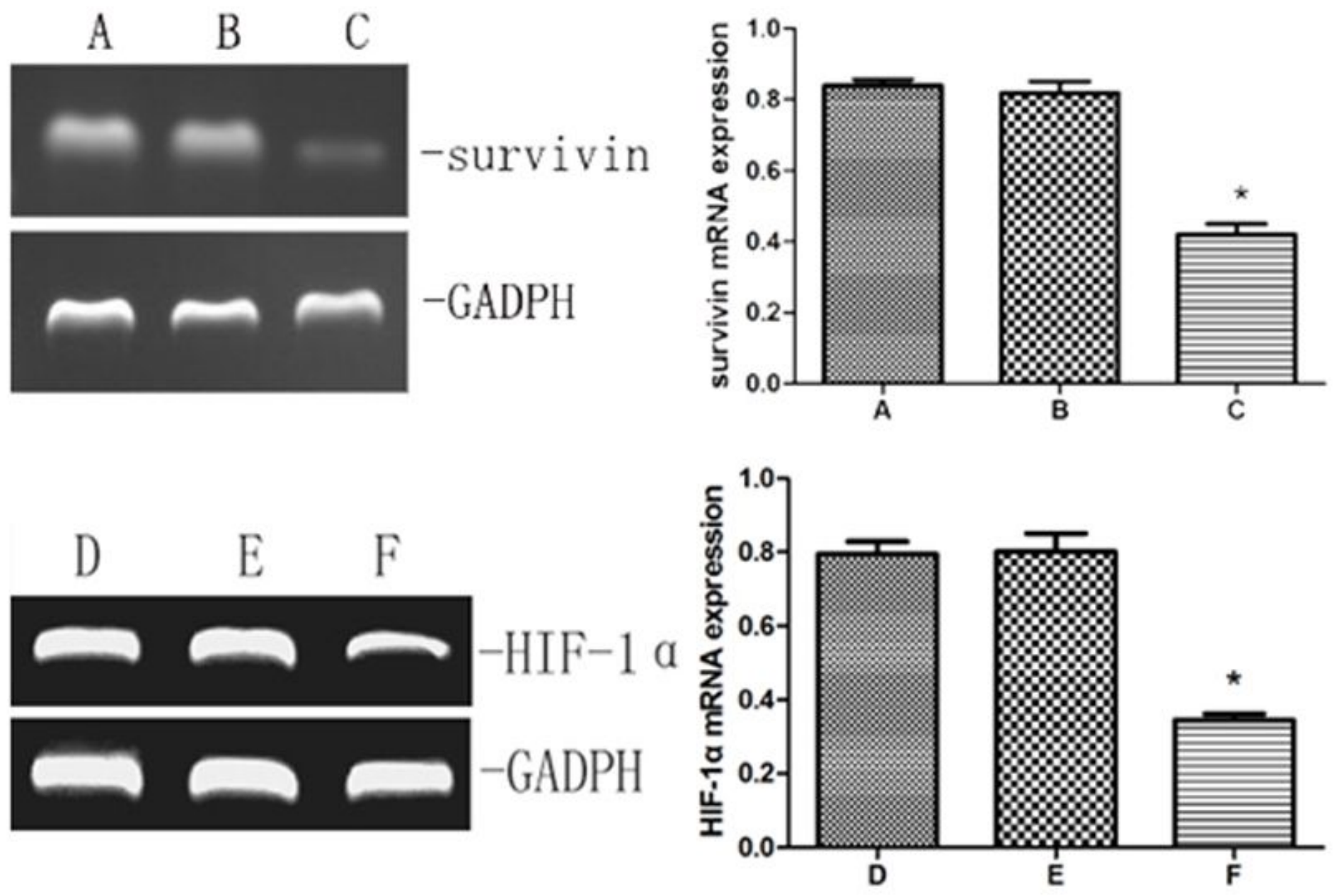

Figure 3

Individual inhibitive effects of siRNAs on HIF-1a and survivin mRNA levels under hypoxia Note: GAPDH was used as internal control and normalized to $100 \%$. The results were similar in three separate experiments. A, D\&Blank control group; B, E: SCR control group C, F: siRNA-Survivin+siRNA-HIF-1a group (sis+siH group). ${ }^{*}<0.05$ vs. the control.
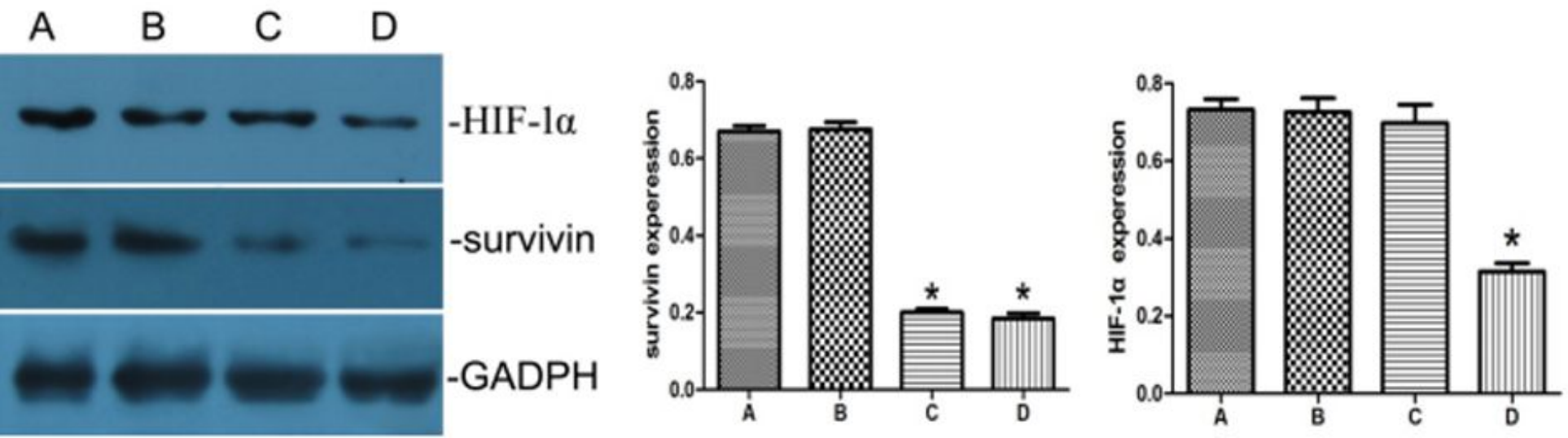

Figure 4 
Inhibitory effects of siRNAs on HIF-1a and survivin proteins under hypoxia Note: GAPDH was used as internal control and normalized to $100 \%$. The results were similar in three separate experiments. A囚Blank control group; B: SCR control group; C: siRNA-Survivin group (sis group); D: siRNA-Survivin+siRNA-HIF-1a group (sis+siH group) .*P $<0.05$ vs. the control.

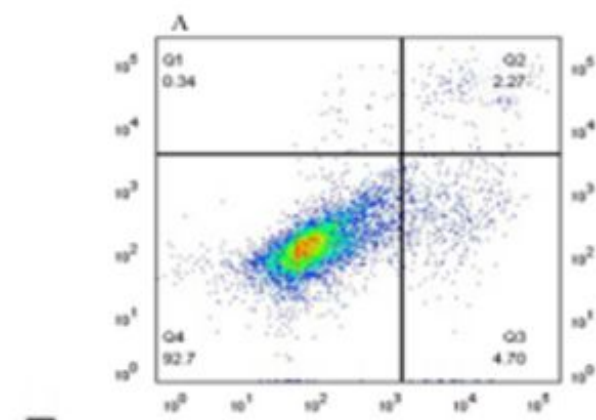

$\bar{\alpha}$
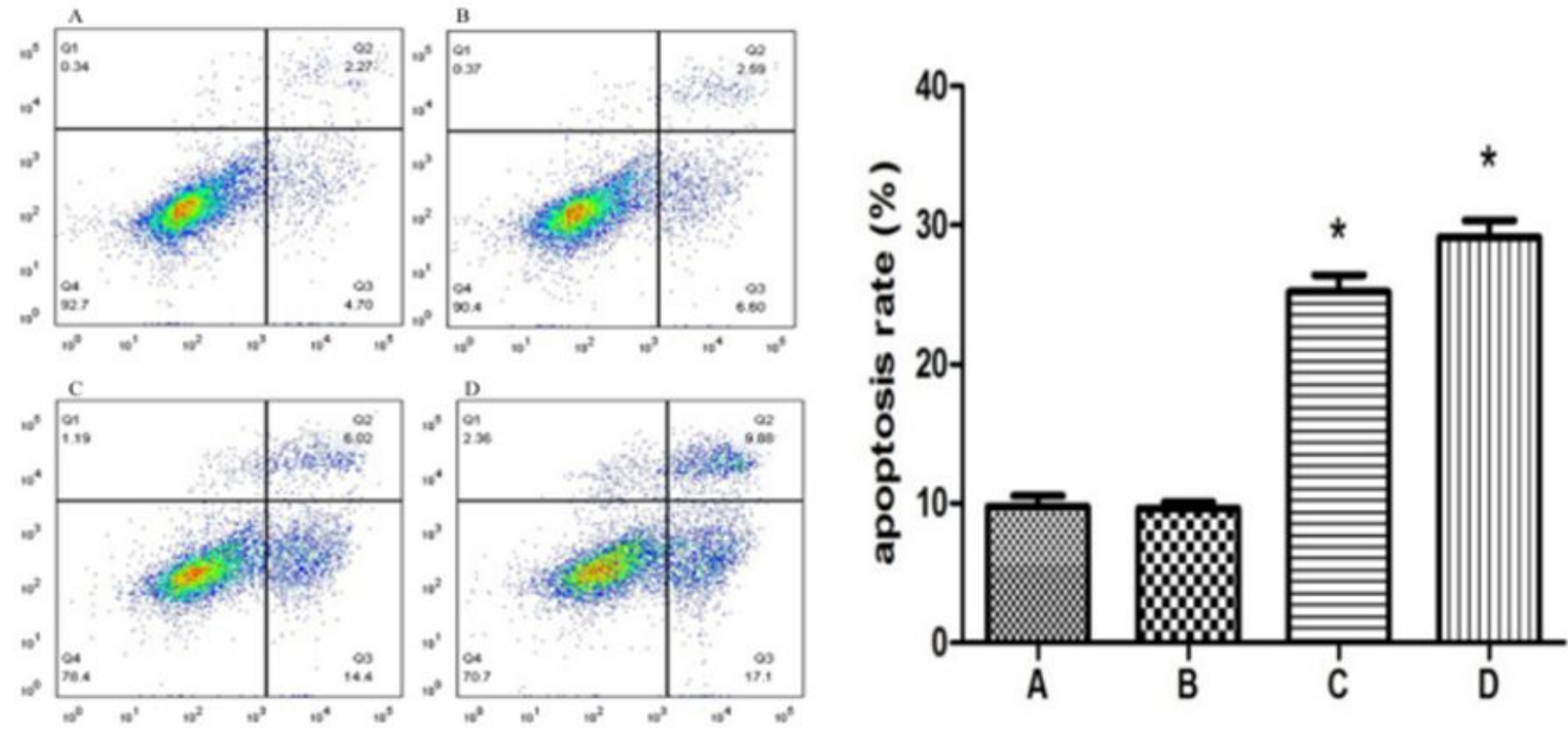

Annexin-FITC

Figure 5

Effects of siRNA silencing of HIF-1a and survivin on apoptosis in SGC-7901 cells Note: Cell apoptosis was assayed by flow cytometry. PI was used for cell nucleus staining and annexin V-FITC for cytomembrane staining. Ratio of apoptosis cells was presented as the standard error of the mean $( \pm$ SEM). ${ }^{*}<<0.05$ vs. the control. 

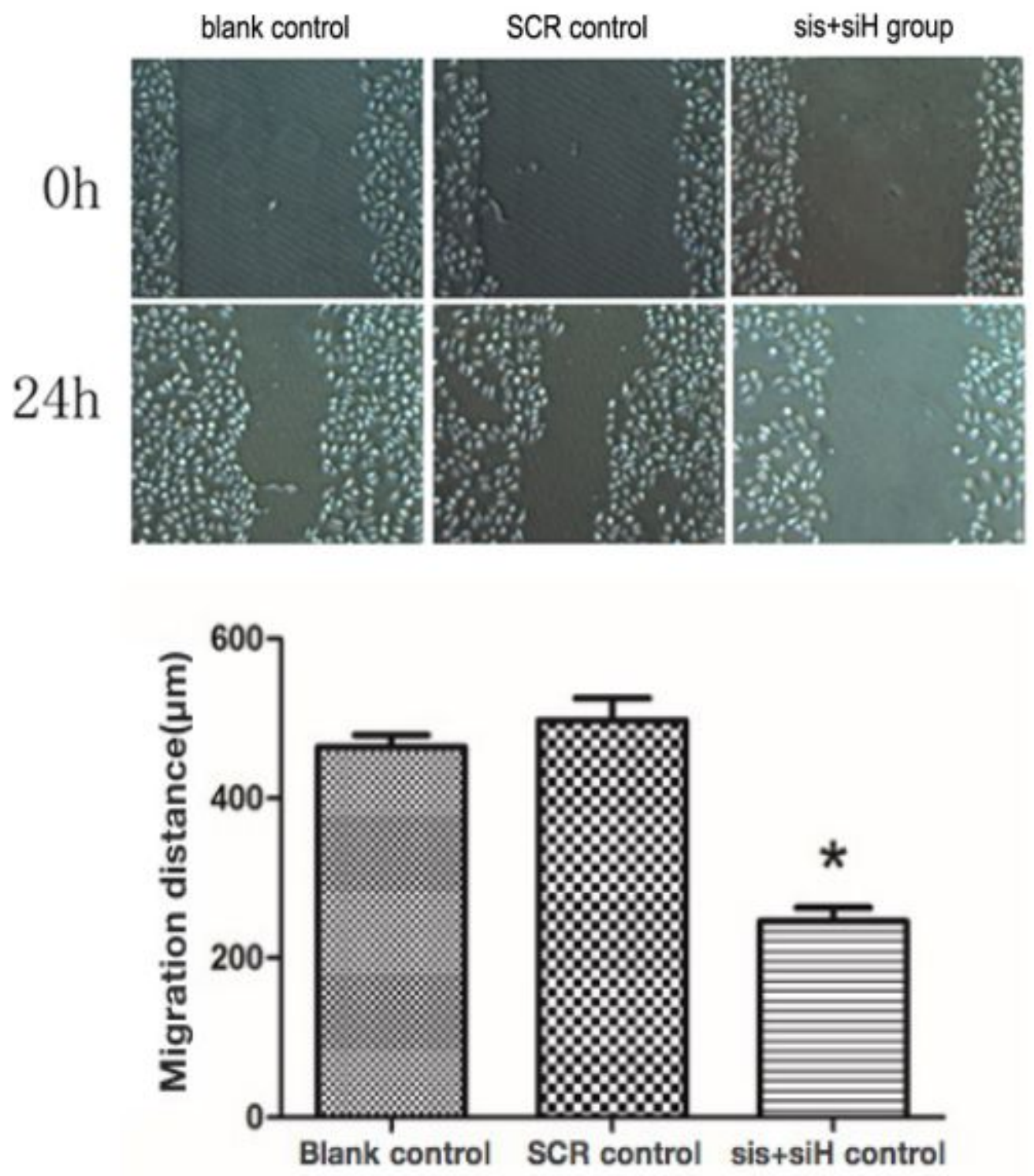

Figure 6

Effect of HIF-1a or/and survivin RNAi on the migration abilities of SGC-7901 cells under hypoxia Note: *P $<0.05$ vs. the control. 

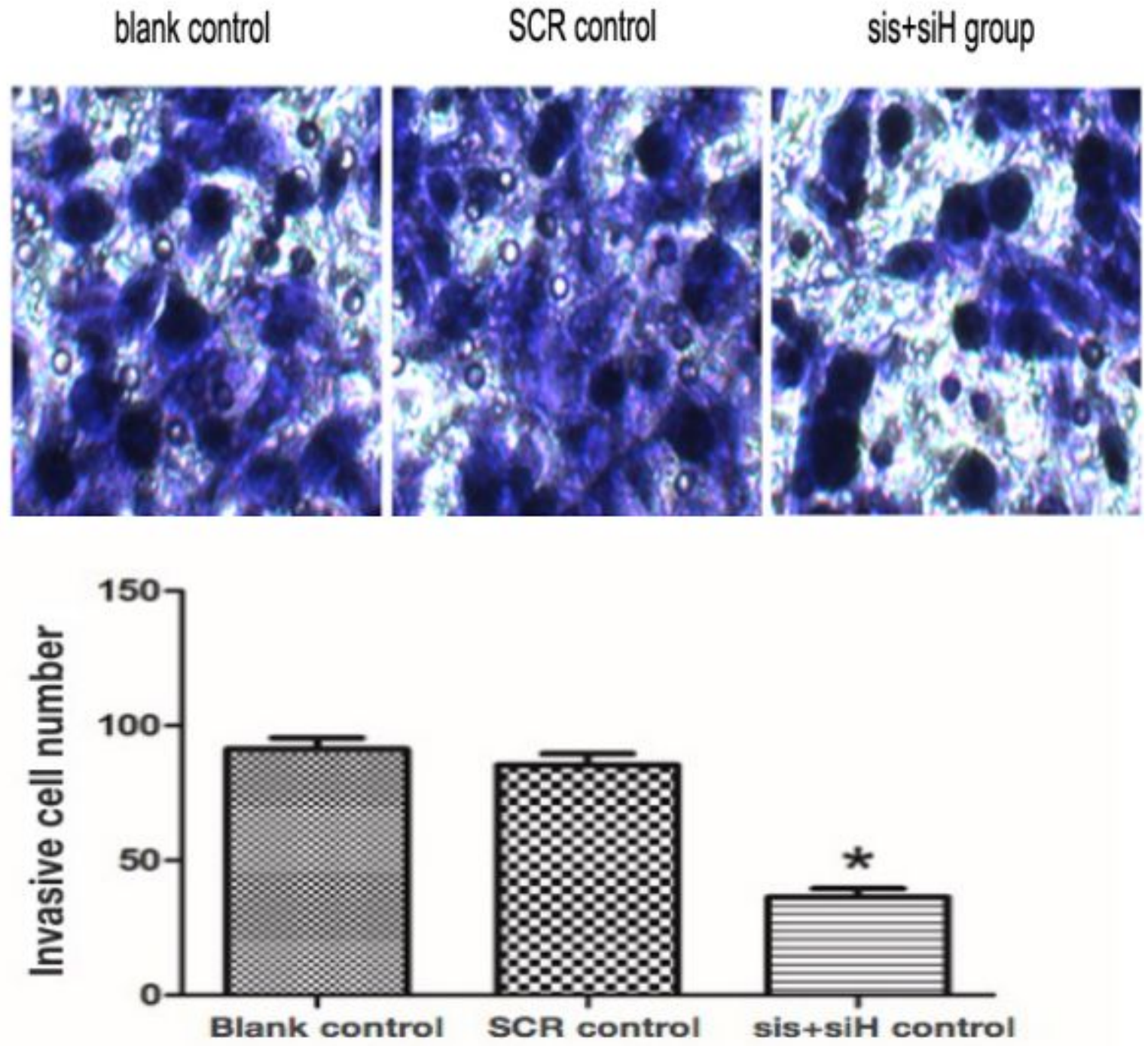

Figure 7

Effect of HIF-1a or/and survivin RNAi on the invasion abilities of SGC-7901 cells under hypoxia Note: *P < 0.05 vs. the control. 